metric vessels and those we have obtained with embryonic and carcinoma cells by tissue culture procedures. The rates of glucose consumption and lactic acid production are of the same order for embryonic cells and normal leucocytes and are greater in each case than the values for the corresponding malignant cells.

A detailed account of this work is being prepared for publication. We wish to thank Dr. F. W. Sheffield, Department of Bacteriology, University College, London, and Dr. Alice E. Moore, Sloan-Kettering Institute for Cancer Research, New York, for kindly sending us the HeLa, and the HEP 1 and 2 strains respectively. One of us (W. C. F.) wishes to acknowledge the award of a grant by the Medical Research Council.

Note added in proof. The transformation of tissue culture lines of human epithelial cells to neoplastic forms has recently been established by cytological and inoculation techniques?.

I. LESLIE W. C. Fulton

R. SINCLAIR

Biochemistry Department,

The Queen's University, Belfast. Aug. 23.

1 Goldblatt, H., and Cameron, G., J. Exp. Med., 97, 525 (1953). Sanford, K. K., Likely,

Healy, G. M., Fisher, D. C., and Parker, R. C., Proc. Soc. Exp. Biol. Med., 89, 71 (1955).

" Vendrely, R., "The Nucleic Acids" (ed. Chargaff, E., and Davidson, J. N.), 2, Chap. 19 (Academic Press, 1955)

- Mellors, R. C., Cancer Res., 15, 557 (1955).

5 Weinhouse, S., "Adv. Cancer Res.", 3, 269 (1955).

- Warburg, O., Seience, 123, 309 (1956).

? Woods M. W Wight K. Hunter, J., and Burk, D., Biochim. Biophys. Acta, 12, 329 (1953).

Beck, W. S., and Valentine, W. N., Cancer Res., 13, 309 (1953).

- Moore, A. E., Southam, C. M., and Sternberg, S. S., Science, 124, 127 (1956).

\section{An Apparatus for eluting and concentrating Chromatogram Spots}

A Major problem in toxicological analysis is the separation of the poison from metabolites and body constituents that are co-extracted. This problem is especially acute in cases of poisoning by alkaloids. One technique that is of great use in solving this problem is paper chromatography ${ }^{1-3}$. The next step in the analysis is the identification of the alkaloid by such techniques as ultra-violet spectrophotometry, micro-colour tests and observations of the form of crystals obtained with various reagents. Recently, Clarke and Williams ${ }^{4}$ have described a technique whereby $0.05 \mathrm{ml}$. of a solution containing $50 \mu \mathrm{gm}$. of alkaloid provides sufficient material for five hundred separate micro-colour and crystal tests. This quantity of alkaloid $(50 \mu \mathrm{gm}$.) is about the amount most suited for initial purification by paper chromatography. We have, however, found difficulty in eluting the alkaloid from the chromatogram and concentrating the eluate into $0.05 \mathrm{ml}$. of solution without loss of alkaloid. A simple and highly efficient apparatus for accomplishing this operation is shown in Fig. 1.

The apparatus consists of a length of $1-\mathrm{mm}$. bore capillary tubing the ends of which are blown into small bulbs. The tubing is then bent as shown in the diagram. The spot cut from the paper is put in the larger right-hand cup and alcohol is dropped on to it from a burette, or siphoned on from a constanthead reservoir levelled with the solvent in the appa-

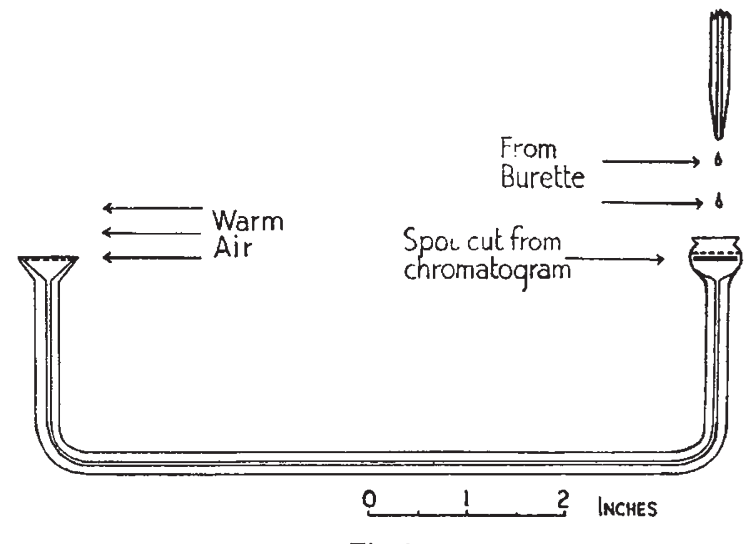

Fig. 1

ratus. An electric hair-drier blows a stream of warm air over the left-hand cup and as evaporation proceeds the paper spot is constantly washed by the addition of fresh alcohol. Concentration of eluted alkaloid occurs in the left-hand cup.

Experiments with spirit-soluble dye have shown that back-diffusion is negligible. While $50 \mu \mathrm{gm}$. of strychnine from a chromatogram run in butanolacetic acid was quantitatively recovered and concentrated into $0.1 \mathrm{ml}$. using this apparatus, only 49 per cent of $50 \mu \mathrm{gm}$. of strychnine on a similar spot was recovered by soaking the paper in $5 \mathrm{ml}$. of alcohol for $5 \mathrm{hr}$. Quantitative measurements were by ultraviolet spectrophotometry.

Many alkaloids have an extremely low absorption in the ultra-violet. Atropine, for example, has peaks with $E$ (l per cent, $1 \mathrm{~cm}$.) approximately 5 . Nevertheless, if $100 \mu \mathrm{gm}$. of atropine can be concentrated into $0.5 \mathrm{ml}$. then optical density values of 0.1 will be obtained. This apparatus, coupled with paper chromatography and the use of micro cells for ultraviolet spectrophotometry, enables accurate measurements to be made for such alkaloids.

We have found it advantageous to concentrate the eluate in two stages ; first, into a volume of approximately $0.15 \mathrm{ml}$. and, secondly, using a micro-scale version of the apparatus, into approximately $0.05 \mathrm{ml}$.

The technique can obviously not bo used for alkaloids run on a buffered paper chromatogram ${ }^{3}$, but where butanol-acetic acid solvents have been used alcohol is an ideal eluent. The rate of evaporation is such that complete solvent exchange (approximately $1.0 \mathrm{ml}$.) in the apparatus is achieved in approximately 20 min. The rate of extraction depends on the compound. To achieve complete extraction we find it best to evaporate for approximately three hours, then to allow the paper to soak overnight and to evaporate for a further three hours the following morning.

This technique is obviously applicable to other problems requiring micro-continuous extraction and concentration. We hope to show further uses of it in forensic chemistry.

\section{F. G. TRYHORN} A. S. CURRY

Home Office Forensic Science Laboratory,

Haddon Lodge, 32 Rutland Drive, Harrogate. Sept. 7.

${ }^{1}$ Mannering, Dixon, Carroll and Cope, J. Lab. Clin. Med., 44, 292 (1954).

${ }^{2}$ Munier, Macheboeuf and Cherrier, Bull. Soc. Chim. Biol., 34, 204 (1952).

'Curry, A. S., and Powell, H., Nature, 173, 1143 (1954).

- Clarke and Williams, J. Pharm. Pharmacol., 7, 255 (1955). 